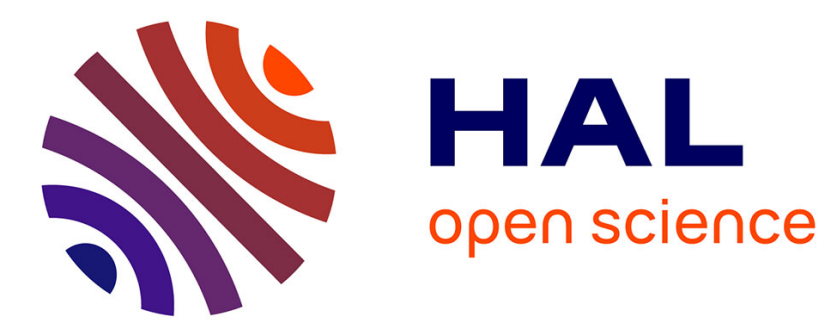

\title{
Time-Resolved in situ Synchrotron X-ray Diffraction Studies of Type 1 Silicon Clathrate Formation
}

\author{
Peter T. Hutchins, Olivier Leynaud, Luke A. O’Dell, Mark E. Smith, Paul
} Barnes, Paul Mcmillan

\section{- To cite this version:}

Peter T. Hutchins, Olivier Leynaud, Luke A. O'Dell, Mark E. Smith, Paul Barnes, et al.. TimeResolved in situ Synchrotron X-ray Diffraction Studies of Type 1 Silicon Clathrate Formation. Chemistry of Materials, 2011, 23 (23), pp.5160-5167. 10.1021/cm2018136 . hal-00993017

\section{HAL Id: hal-00993017 https://hal.science/hal-00993017}

Submitted on 19 May 2014

HAL is a multi-disciplinary open access archive for the deposit and dissemination of scientific research documents, whether they are published or not. The documents may come from teaching and research institutions in France or abroad, or from public or private research centers.
L'archive ouverte pluridisciplinaire HAL, est destinée au dépôt et à la diffusion de documents scientifiques de niveau recherche, publiés ou non, émanant des établissements d'enseignement et de recherche français ou étrangers, des laboratoires publics ou privés. 


\title{
Time-Resolved in situ Synchrotron X-ray Diffraction Studies of Type 1 Silicon Clathrate Formation
}

\author{
Peter T. Hutchins ${ }^{1 \dagger}$, Olivier Leynaud ${ }^{1,2 \dagger+}$, Luke A. O’Dell ${ }^{3 \dagger \dagger}$, \\ Mark E. Smith ${ }^{3}$, Paul Barnes* ${ }^{1,2}$ and Paul F. McMillan*,1
}

1: Department of Chemistry and Materials Chemistry Centre, Christopher Ingold Laboratory, University College London, 20 Gordon Street, London, WC1H 0AJ, UK.

2: School of Crystallography, Birkbeck College, University of London, Malet Street, London, WC1E 7HX, UK

3: Department of Physics, University of Warwick, Coventry CV4 7AL, UK.

${ }^{\dagger}$ Present address: Infineum UK Ltd., Infineum Business \& Technology Centre, PO Box 1, Milton Hill, Abingdon, Oxon. OX13 6AE, U.K.

†† Present address: Institut Néel, CNRS Université Joseph Fourier, B.P. 166, F-38042 Grenoble Cedex 9, France.

${ }^{\dagger \dagger}$ Present address: Steacie Institute for Molecular Science, National Research Council, 100 Sussex Drive, Ottawa ON, K1N 5A2, Canada.

Corresponding authors’ E-mail: p.barnes@mail.cryst.bbk.ac.uk; p.f.mcmillan@ucl.ac.uk 


\begin{abstract}
Silicon clathrates are unusual open-framework solids formed by tetrahedrally-bonded silicon that show remarkable electronic and thermal properties. The type I structure has a primitive cubic unit cell containing cages occupied by metal atoms to give compositions such as $\mathrm{Na}_{8} \mathrm{Si}_{46}$ or $\mathrm{Na}_{2} \mathrm{Ba}_{6} \mathrm{Si}_{46}$. Although their structure and properties are well described there is little understanding of the formation mechanism. $\mathrm{Na}_{8} \mathrm{Si}_{46}$ is typically produced by metastable thermal decomposition under vacuum conditions from $\mathrm{NaSi}$, itself an unusual structure containing $\mathrm{Si}_{4}{ }^{4-}$ poly-anions. In this study we used in situ synchrotron X-ray diffraction combined with rapid X-ray detection on samples taken through a controlled temperature ramp $\left(25-500^{\circ} \mathrm{C}\right.$ at $8 \%$ min) under vacuum conditions $\left(10^{-4}\right.$ bar), to study the clathrate formation reaction. We also carried out complementary in situ high temperature solid state ${ }^{23} \mathrm{Na}$ NMR experiments using a sealed tube loaded under inert gas atmosphere conditions. We find no evidence for an intermediate amorphous phase during clathrate formation. Instead we observe an unexpectedly high degree of structural coherency between the $\mathrm{Na}_{8} \mathrm{Si}_{46}$ clathrate and its $\mathrm{NaSi}$ precursor, evidenced by a smooth passage of several X-ray reflections from one structure into the other. The results indicate the possibility of an unusual, epitaxial-like, growth of the clathrate phase as $\mathrm{Na}$ atoms are removed from the $\mathrm{NaSi}$ precursor into the vacuum.
\end{abstract}

\title{
Keywords:
}

silicon clathrate; $\mathrm{Na}_{8} \mathrm{Si}_{46}$; Zintl phase; $\mathrm{NaSi}$; solid state synthesis; synchrotron radiation; $\mathrm{X}$ ray diffraction; NMR spectroscopy; in situ studies 


\section{Introduction}

Semiconductor clathrates, based on tetrahedrally-bonded networks of elements in groups 1315 of the periodic table, form a large family of unusual open-framework structures that exhibit remarkable and potentially useful electronic and thermal properties. ${ }^{1-15}$ The framework composed from $\mathrm{sp}^{3}$ bonded atoms is intrinsically semiconducting. However the structures usually contain electropositive metal atoms located within the clathrate cages that inject electrons into the conduction band to produce metallic or narrow-gap semiconducting phases. The result is a wide range of materials with electronic properties ranging from metallic to wide-gap-semiconducting, depending on the cage and framework site occupancy. In addition to the electronic behavior, "rattling" vibrations of metal guest atoms affect the phonon propagation properties resulting in lowered thermal conductivity and potentially useful thermoelectric properties. Sharp peaks near the Fermi level in the electronic density of states result in large Seebeck coefficients and also superconductivity for Ba-containing members. ${ }^{3,4,16-30}$

Two main structural types were described during the initial studies of $\mathrm{Si}$ and Ge clathrate materials. $^{1-9}$ The type I clathrate has a primitive cubic structure (Pm3n: $\mathrm{a}_{\mathrm{o}} \sim 10.2 \AA$ ) based on dodecahedral $\left[5^{12}\right]$ and tetrakaidecahedral $\left[5^{12} 6^{2}\right]$ cages that are occupied by metal guest atoms to produce metallic $\mathrm{Na}_{8} \mathrm{Si}_{46}$ whose formation is studied here. Studies on Ge and $\mathrm{Sn}$ clathrates gave rise to narrow gap semiconducting materials with compositions like $\mathrm{K}_{8} \mathrm{Ge}_{44}$ or $\mathrm{Rb}_{8} \mathrm{Sn}_{44}$, where the metal oxidation is compensated by formation of vacancies in the clathrate framework. Compound clathrates such as $\mathrm{Sr}_{8} \mathrm{Ga}_{16} \mathrm{Ge}_{30}$ have fully occupied frameworks and achieve charge balance by introduction of group 13 elements. Metal-deficient clathrates such as $\mathrm{K}_{7} \mathrm{Si}_{46}$ are also known. It was recently shown that molecular $\mathrm{H}_{2}$ can be incorporated in the clathrate cage sites to form materials such as $\mathrm{Na}_{8-\mathrm{x}}\left(\mathrm{H}_{2}\right)_{\mathrm{x}} \mathrm{Si}_{46}{ }^{31}$ In addition to the type I structure, type II clathrates can also be formed. These have an $f c c$ structure containing 136 framework (T) atoms within the $F d \overline{3} m$ cell (a $\sim 14.6 \AA$ A), with 16 "small" ([5 $\left.\left.{ }^{12}\right]\right)$ and 8 "large" ( $\left[5^{12} 6^{4}\right]$ cages that are completely or partially filled to yield clathrates such as $\mathrm{Na}_{\mathrm{x}} \mathrm{Si}_{136}(\mathrm{x}=0$ 24) or $\mathrm{Cs}_{8} \mathrm{Na}_{16} \mathrm{Si}_{136}$. Examples of further clathrates with a hexagonal structure have now also been described. ${ }^{10,13,14}$

The structure and chemistry of these materials is compatible with existing semiconductor technology and it is essential to understand and control their synthesis in bulk and thin film 
form to develop future applications. However, although much is known about their structures and physical properties, there is little understanding of the clathrate formation mechanisms. The Si and Ge materials are usually prepared by partial thermal decomposition of Zintl compounds like $\mathrm{NaSi}$ under vacuum conditions. Clathrates such as $\mathrm{Na}_{8} \mathrm{Si}_{46}$ (type I) and $\mathrm{Na}_{\mathrm{x}} \mathrm{Si}_{136}$ (type II: $\mathrm{x}=4-24$ ) are produced with varying target temperature and ramp rate, vacuum conditions etc. The clathrate compounds are metastable under the synthesis conditions, with respect to diamond-structured $\mathrm{Si}$ at ambient pressure, but it has been suggested that slightly negative pressures achieved under tensile strains, that are readily

achieved during epitaxy on $\mathrm{Si}$ surfaces, could result in stabilization of the clathrate phase. ${ }^{32}$ Growth of the NaSi precursor on Si has now been demonstrated, leading to the possibility of thin film synthesis. ${ }^{33}$ In this study we have used in situ synchrotron X-ray diffraction techniques, combined with rapid collection of the full pattern obtained during temperature ramp and vacuum conditions, to investigate the formation of $\mathrm{Na}_{8} \mathrm{Si}_{46}$ clathrate from $\mathrm{NaSi}$. We have also carried out ${ }^{23} \mathrm{Na}$ solid state NMR experiments to study the NaSi phase at high temperatures immediately preceding the clathrate formation reaction. The results provide a unique view of the clathrate formation process and suggest an unusual epitaxial-like relationship between the NaSi phase at high temperature, as it loses its $\mathrm{Na}$ component into the vapor phase, and the $\mathrm{Na}_{8} \mathrm{Si}_{46}$ clathrate that grows at the sample surface.

\section{Experiment and Methods Section}

The synthesis of clathrate phases, including $\mathrm{Na}_{8} \mathrm{Si}_{46}$ as well as type $\mathrm{II} \mathrm{Na}_{\mathrm{x}} \mathrm{Si}_{136}$ ( $\left.\mathrm{x}=4-24\right)$ materials, typically involves a metastable thermal decomposition reaction under dynamic vacuum conditions starting with the Zintl compound NaSi: ${ }^{1,3,4,8,9,15}$

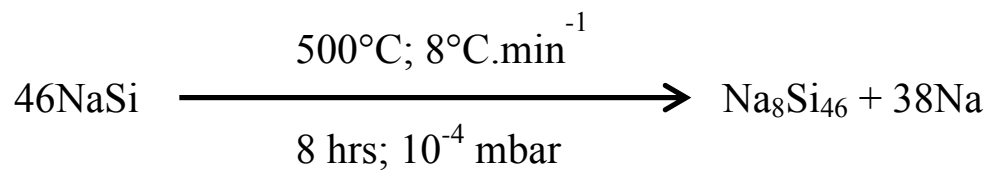

The reactant and product structures have very different architectures and it has therefore been generally assumed that nucleation and growth of the clathrate phase proceeds heterogeneously, perhaps via an amorphous $\mathrm{Na}_{\mathrm{x}} \mathrm{Si}$ layer formed at the Zintl phase surface as 
$\mathrm{Na}$ atoms are removed into the vacuum. Here we have exploited recently-developed in situ synchrotron X-ray diffraction techniques to obtain time-resolved structural data during the course of clathrate synthesis reaction. In earlier work of this kind, where tailor-made environmental cells were necessary to deliver highly specialized conditions to the sample, in situ data collection was more conveniently carried out by exploiting the adaptability of either white beam energy-dispersive X-ray diffraction ${ }^{34}$ or neutron diffraction ${ }^{35}$ techniques. However similar capabilities can now be achieved with angle-scanning X-ray diffractometers using specially designed capillary-based environmental cells and rapid detector systems that can deliver time-resolved X-ray diffraction data of sufficient time and angular resolution to permit meaningful dynamic structural refinement. The high-vacuum and controlled hightemperature in situ conditions required for following the clathrate formation from NaSi were achieved here by designed adaptation of a capillary-based in situ environmental reaction cell. $^{36}$ The resulting combination offered a unique opportunity to study the clathrate formation mechanism directly.

The starting material, $\mathrm{NaSi}$, was prepared from mixtures of the elements ( $\mathrm{Si}, 99.999 \%$; $\mathrm{Na}$, 99.95\%) in a dry box. $15 \mathrm{~mol} \%$ excess $\mathrm{Na}$ was added to counter evaporation loss during synthesis. The mixture was placed in a Ta crucible and heated in a steel autoclave at $600{ }^{\circ} \mathrm{C}$ for 24 hours. In situ time-resolved X-ray diffraction experiments were carried out at station $6.2^{37}$ of the synchrotron radiation source (SRS) at Daresbury, UK using an incident beam energy of $8.856 \mathrm{keV}(\lambda=1.429 \AA)$. The $R A P I D 2^{38}$ position-sensitive detector enabled medium-high angular resolution data $\left(\Delta(2 \theta) \sim 0.06^{\circ}\right)$ to be collected on a timescale of a few seconds at each temperature using the high-T (high temperature) in situ cell. For this study the environmental cell was configured to provide controlled entry of the air-/moisture-sensitive samples into the capillary which was also coupled to a vacuum $\left(10^{-4} \mathrm{mbar}\right)$ system. During data collection the sample was heated at $8^{\circ} \mathrm{C} / \mathrm{min}$ up to $500^{\circ} \mathrm{C}$ after which the temperature was held constant.

The computational package FullProf/WinPLOTR program ${ }^{39,40}$ was used for Le Bail ${ }^{41}$ and Rietveld ${ }^{42}$ unit cell/structural refinements which were applied in interactive mode across the whole time/temperature-resolved diffraction data set using the multi-phase refinement option assigned to the $\mathrm{NaSi}$ and $\mathrm{Na}_{8} \mathrm{Si}_{46}$ clathrate structures. The structures reported by Witte et al. ${ }^{43}$ and Ramachandran et al. ${ }^{9}$ were used as starting points for refinements of the two phases. The multi-phase analysis option permitted us to examine whether the synthesis proceeded via a 
continuous route or else involved sharp transitions between two or more structure types. The obtained $\mathrm{R}_{\text {Bragg }}$ values were typically around $10-25 \%$ but increased to $40 \%$ or more for temperatures where one phase was much less-well defined. The X-ray diffraction patterns of both structures show unusual and remarkable convergence between several of the peak positions, as the temperature is increased. This result suggests some structural coherency exists between the two apparently unrelated phases. We have discussed possible models for this behavior below. However, the in situ nature of the experiment, with both $\mathrm{NaSi}$ and clathrate phases present together and evolving during the high-T synthesis study, precluded the detailed level of structural refinement that is achieved during normal crystallographic structure determination studies on pure phases under constant conditions. In this case the in situ data are complicated yet further by peaks shifting rapidly due to the very high thermal expansion of the NaSi phase. However, the results are within normal bounds for multiphase in situ data refinement across a continuous reaction sequence and, provided fine structural details are not being sought, they are easily of sufficient quality to provide thermal expansion data or to identify major features such as a phase transformation occurring during synthesis.

For high-T NMR studies we developed a specialized probe ${ }^{44,45}$ based on an L-shaped $\mathrm{SiO}_{2}$ glass sample holder that was loaded and sealed in the inert (Ar) atmosphere of the dry-box. Static ${ }^{23} \mathrm{Na}$ NMR spectra were recorded at $7.05 \mathrm{~T}$ : the chemical shift reference was $1 \mathrm{M}$ aqueous $\mathrm{NaCl}(79.386 \mathrm{MHz})$. Heating was achieved via a $\mathrm{Ni} / \mathrm{Cr}$ coil wound with its axis parallel to the magnetic field. Temperature calibration to within $\pm 5^{\circ} \mathrm{C}$ was achieved beforehand using a thermocouple embedded in $\mathrm{MgO}$ powder placed within the RF coil. After adjusting the power, one hour was allowed for the sample temperature to equilibrate. Single pulse excitation was used with a $3 \mu$ s pulse width (approximately $90^{\circ}$ tip angle). A 1 s recycle delay was used to achieve an acceptable signal to noise ratio in the experiment ( $\sim 30$ minutes).

\section{Results and Discussion}

\section{Single Temperature Ramp Experiments}

A typical in situ dataset, obtained during high- $\mathrm{T}$ treatment of $\mathrm{NaSi}$ and resulting in production of $\mathrm{Na}_{8} \mathrm{Si}_{46}$ clathrate, is shown in Figure 1. The data were recorded over 512 detector wires and interpolated to 4096 channels over a $2 \theta$-range of $5-65^{\circ}$ with absolute $2 \theta$ positions calibrated against the Si powder standard. The in situ conditions were set to generate a temperature 
ramp of $8^{\circ} \mathrm{C} \cdot \mathrm{min}^{-1}$ from room temperature to the target $500^{\circ} \mathrm{C}$ under a vacuum of $10^{-4}$ bar. Diffraction data were collected every 30 seconds for the first 3 hours, and then every minute thereafter. Figure 1a provides an overall view of the diffraction patterns showing that most changes occurred during the first 75 minutes, i.e., within the first 10 displayed patterns (corresponding to a full set of 150 collected patterns), during which time the temperature had reached the $500^{\circ} \mathrm{C}$ target plateau. During this period the NaSi pattern exhibited substantial shifts in peak positions and changes in relative intensities due to large thermal expansion and loss of the Na-component at higher $\mathrm{T}$, followed by onset of peaks due to $\mathrm{Na}_{8} \mathrm{Si}_{46}$ clathrate formation. Once the clathrate phase had formed and become established within the sample, little further change occurred until the sample capillary was destroyed, following attack by the evolved sodium vapor, and the diffraction pattern was then lost.

Figs. $1 \mathrm{~b}$ and $1 \mathrm{c}$ present expanded views of important regions of the data that demonstrate the appearance of clathrate peaks after 59-60 minutes, just as the target $500^{\circ} \mathrm{C}$ is reached. The most striking aspect of the data during the initial heating phase is the remarkable shift with temperature of the NaSi peaks to lower $2 \theta$, during the initial period before the onset of the reaction, indicating a very large thermal expansion coefficient $\left(4.54 \times 10^{-5}{ }^{\circ} \mathrm{C}^{-1}\right)$ for the Nasilicide phase, which is comparable with those observed for ionic conductors. Another main feature is the lack of any reduction in crystalline peak intensities and the absence of amorphous scattering in the range over which clathrate formation takes place. This observation indicates that the clathrate synthesis proceeds smoothly from the Zintl phase. In fact the evidence is that the clathrate formation occurs continuously and with a structural relationship to the Zintl phase; that is, several reflections that are indexed as part of the $\mathrm{NaSi}$ pattern at room temperature appear to become attributable to the Si-clathrate phase; examples of such peaks with apparent "dual ownership" are listed in Table 1.

The variations in unit cell parameters for the NaSi and Si-clathrate phases during the vacuum heating and synthesis process were studied using Le Bail and Rietveld approaches to refine the powder X-ray diffraction data. All diffraction patterns were first fitted to the $\mathrm{NaSi}$ and $\mathrm{Na}_{8} \mathrm{Si}_{46}$ clathrate phases using le Bail refinement and, after inspection, the le Bail output was then used to provide initial starting cell parameters for multi-phase Rietveld refinement for the two structures. Figure 2 shows an example of this procedure carried out for the end point of the synthesis at $500^{\circ} \mathrm{C}$ when the composition is predominantly of a clathrate nature. The Supplementary Information gives similar Rietveld plots, together with the associated 
structural/refinement data, for three representative stages of the overall synthesis process. Figure 3 charts the overall variations in unit cell volume over the synthesis; variations in other thermal/structural parameters are also illustrated in the Supplementary Information. As already noted, the NaSi phase exhibits unusually large thermal expansion, up to the point of onset of clathrate formation $\left(\sim 60 \mathrm{~min} ., 500^{\circ} \mathrm{C}\right)$. After this there is an anomalous reduction in the unit cell volume; this point also coincides with a drop in vacuum observed in the system. Although these observations do not provide absolute proof, together they do indicate that $\mathrm{Na}$ is lost in the form of vapor from the structure from around and after the point of clathrate formation, as expected from reaction (1), Sodium loss from the NaSi structure must be accompanied by reduction of $\mathrm{Na}^{+}$to $\mathrm{Na}^{\mathrm{o}}$ species and $\mathrm{Si}-\mathrm{Si}$ bond formation. ${ }^{46-48}$ It is likely that the cages in the clathrate structure are formed around the remaining $\mathrm{Na}$ atoms that then act as templates for the microporous crystalline solid.

Comparison of the evolution of selected features of the $\mathrm{NaSi}$ silicide and $\mathrm{Na}_{8} \mathrm{Si}_{46}$ clathrate diffraction patterns provides new clues as to the nature of the solid state reaction process. The $\mathrm{NaSi}$ structure contains isolated $\mathrm{Si}^{4-}{ }_{4}$ tetrahedra separated by $\mathrm{Na}^{+}$ions, in contrast with the $\mathrm{Na}_{8} \mathrm{Si}_{46}$ clathrate structure with its open-framework cages. The respective space groups are monoclinic $\mathrm{C} 2 / \mathrm{c}(\mathrm{NaSi})$ and cubic Pm3n (type 1 clathrate). The two compounds have different stoichiometries and so it is not possible to identify a true crystallographic group/subgroup relationship between the two structures. In Figure 4a,b we compare the overall structural features of the two phases. We first consider the NaSi (-202) planes and clathrate (200) planes that have already been linked because of their similar lattice spacing and apparent propagation of one into the other as the synthesis reaction proceeds (Figure 1, Table 1). The -202 planes for NaSi pass through $\mathrm{Na}^{+}$sites that then become the centers of pentagonal dodecahedral and tetrakaidecahedral cage sites occupied by $\mathrm{Na}$ atoms in the clathrate structure. Figure $4 \mathrm{c}$ shows that this is both feasible and likely: the occupation of the NaSi (-202) planes by $\mathrm{Na}^{+}$cations is such that they effectively constitute "sodium sheets" providing an easy transfer route to the new composition and cage environment, following $\mathrm{Na}$ loss to the vacuum from the initial Zintl phase structure. The results of Rietveld refinements of the X-ray data support this idea in that, as the temperature is raised, large excursions of the $\mathrm{Na}^{+}$cations around their starting positions occur, accompanied by flattening and elongation of the $\mathrm{Si}_{4}{ }^{4-}$ tetrahedra. This trend can also be perceived from the change in behavior of $\mathrm{Na}$ thermal parameters after 80 min with the temperature at $500^{\circ} \mathrm{C}$ (see Supporting Information). 
However, due to the highly correlated nature of thermal/occupancy parameters from X-ray refinement, we sought independent confirmation from high-T ${ }^{23} \mathrm{Na}$ NMR spectroscopy.

The in situ high-T NMR studies were therefore undertaken to further investigate the response of $\mathrm{Na}$ in the $\mathrm{NaSi}$ structure to increasing temperature. The spectra were obtained using a specially designed probe that permitted examination of $\mathrm{NaSi}$ samples in situ at high temperature, inside a pre-sealed vacuum tube; useful data could be obtained up to $\mathrm{T}=400^{\circ} \mathrm{C}$. At room temperature, the static ${ }^{23} \mathrm{Na}$ signal from NaSi occurs at $\sim 0 \mathrm{ppm}$ consistent with ionic $\mathrm{Na}^{+}$species. The broad asymmetric peak shape occurs due to quadrupolar effects associated with the asymmetry of the local electric field gradient surrounding the spin $I=3 / 2$ nucleus. ${ }^{49-51}$ The slight baseline distortion to the left of the main peak is due to the single pulse experiment that caused some signal loss at the start of the free induction decay; attempts were made to carry out spin echo experiments but there was too little signal to yield useful data. Above $\mathrm{T}$ $250^{\circ} \mathrm{C}$, a considerable reduction in peak width along with an increase in peak symmetry occurs (Figure 5). This observation is consistent with a time-averaged increase in local site symmetry around the $\mathrm{Na}^{+}$ions in the $\mathrm{NaSi}$ structure at high temperature, and perhaps even the onset of $\mathrm{Na}^{+}$mobility between sites indicating possible ionic conduction behavior. No further change in the peak shape or intensity was observed following heating at $400^{\circ} \mathrm{C}$ for up to 10 hours, until the NMR signal was finally lost due to degradation of the glass tube and the $\mathrm{Cu}$ coil, just as the NaSi sample began to undergo significant $\mathrm{Na}$ loss and form clathrate material.

The combined data from the in situ X-ray diffraction and ${ }^{23} \mathrm{Na}$ NMR studies indicate that clathrate formation is linked to thermally-induced $\mathrm{Na}^{+}$motions occurring within the expanded $\mathrm{NaSi}$ lattice, leading to loss of $\mathrm{Na}^{+}$ions that undergo reduction to form $\mathrm{Na}^{\mathrm{o}}$ species in the vapor phase which is pumped away during the vacuum experiment. The $\mathrm{Na}^{+} \rightarrow \mathrm{Na}^{\mathrm{O}}$ reduction is accompanied by formation of new $\mathrm{Si}-\mathrm{Si}$ bonds between the highly distorted $\mathrm{Si}_{4}{ }^{4-}$ tetrahedra of the Zintl phase structure. The data and analysis indicate this process can occur directly, linking the two apparently unrelated structures and without invoking the formation of any intermediate amorphous material. A notable feature is the continuity of X-ray diffraction features between the NaSi and clathrate phases which indicates some type of growth process in which there is structural continuity between elements of both phases at the $\mathrm{NaSi} / \mathrm{Na}_{8} \mathrm{Si}_{46}$ interface. This view is supported by the cell expansion data (Figure 3) which show that in the early stages of clathrate formation (e.g. after 10 minutes heating at $500^{\circ} \mathrm{C}$ ) the unit cell volume of the clathrate is anomalously low (by $\sim 0.14 \%$ ) compared with even the room 
temperature value, but it then rises to the constant value expected for bulk clathrate material as the formation reaction progresses. This behavior is consistent with the quasi-epitaxial growth scenario suggested above. As new clathrate material forms at the Zintl phase surface it becomes structurally coherent with it and is constrained by the unit cell parameters of the substrate, whereas material produced later in the reaction grows out and away from the $\mathrm{NaSi}$ surface and therefore adopts the normal bulk clathrate unit cell value. This effect could also be associated with a slight compositional change in the type I clathrate as it forms. Böhme et al. $^{52}$ have recently reported formation of a Na-deficient variety of $\mathrm{Na}_{8-\mathrm{x}} \mathrm{Si}_{46}$ clathrate with $\mathrm{x}=$ 1.8, produced by reaction between $\mathrm{NaSi}$ and $\mathrm{HCl}$, with a unit cell volume of $1060.6 \AA^{3}$ which is significantly smaller than that obtained with the clathrate produced here. However, experimental and theoretical work on type II $\mathrm{Na}_{\mathrm{x}} \mathrm{Si}_{136}$ clathrates has shown that the unit cell volume remains virtually unchanged as the $\mathrm{Na}$ content is varied. ${ }^{8,9,53}$

\section{Thermal cycling experiments}

In this case temperature ramp-cycling experiments were carried out to further investigate the high temperature behavior of $\mathrm{NaSi}$ and the clathrate formation process. In these experiments repeated heating and cooling cycles were introduced into the synthesis time-temperature profile such that the end-temperature of each successive cycle progressively approached a final target temperature which was set at the same $500^{\circ} \mathrm{C}$; the resultant temperature profile resembles a "sawtooth" shape (Figure 6). These experiments were carried out in a closed tube environment placed under vacuum before the cycling stage rather than under dynamic pumping conditions, so that $\mathrm{Na}$ vapor exsolved from the $\mathrm{NaSi}$ remained inside the sample chamber and could re-react with the solid phase during the cooling part of the cycle. However, after several cycles to progressively higher $\mathrm{T}$ values, some Na reacted with the glass walls of the container and was removed from the system. The X-ray patterns remain dominated by $\mathrm{NaSi}$ throughout, even to the highest temperatures examined $\left(500^{\circ} \mathrm{C}\right)$, indicating the high thermal stability of the Zintl phase in a Na-rich atmosphere. The repeated cycles of large thermal expansion/contraction of the NaSi phase are clearly observed in the figure. However, a new diffraction peak begins to emerge between $28-28.5^{\circ} 2 \theta$ following several temperature cycles (Figure 6). Because of the high expansions involved and correlations between the silicide and clathrate phases, it is difficult to unambiguously identify this peak with the formation of $\mathrm{Na}_{8} \mathrm{Si}_{46}$, or indeed to any other clathrate phase or polymorph of elemental Si (Si-I, Si-III, Si-IV etc) that might form metastably under these conditions. 
Throughout the ramp cycles the peak positions match the high thermal expansion behavior of the NaSi substrate, indicating an intimate structural relationship between the two. In the earlier cycles, the new peak disappears during the highest temperature part of the ramp, when it merges with a NaSi reflection, and re-appears during the lower $\mathrm{T}$ part of the ramp, giving an appearance like that of Barchan dunes marching across a desert landscape. After 6 cycles (when the top temperature reaches $450^{\circ} \mathrm{C}$ or higher) the new peak becomes a permanent feature of the pattern. The same behavior is mirrored by a second new peak appearing near $33^{\circ} 2 \theta \square$ (Figure 6). During this period, the NaSi reflections at $26.7^{\circ}$ and $28.1^{\circ} 2 \theta \square$ undergo weakening, first reversibly during the earlier cycles then permanently after further cycles, which could correspond to the timing of the perceived Na loss from the Zintl phase. We do not yet have a structural interpretation for this new diffraction feature but suggest that, apart from the probability of having clathrate origins, it could correspond to a Na-deficient $\mathrm{NaSi}$ Zintl phase or to a new type of ordered $\mathrm{Na}_{\mathrm{x}} \mathrm{Si}(\mathrm{x}<1)$ structure formed at the surface; many examples of crystalline Zintl compounds with partly polymerized sheet or network polyanions are known, ${ }^{50,51}$ although none have yet been described in the Na-Si system. Regardless of the complete explanation, the unusual appearance of these cyclic ramps serves to highlight the thermal complexity of these systems, the important role played by $\mathrm{Na}$ loss and possible templating actions from the NaSi precursor phase during the earlier stages of the clathrate-forming reaction.

\section{Conclusions}

The results reveal a remarkable formation scenario for $\mathrm{Na}_{8} \mathrm{Si}_{46}$ clathrate under high temperature - high vacuum conditions from the Zintl NaSi phase, suggesting an unusual kind of epitaxial relationship between lattice planes of the two apparently dissimilar structures following indications of sudden $\mathrm{Na}$ loss and high temperature structural distortion of the Zintl phase precursor. They help us understand why the Type $\mathrm{I} \mathrm{Na}_{8} \mathrm{Si}_{46}$ clathrate phase is produced under relatively low vacuum conditions whereas Type II $\mathrm{Na}_{24-\mathrm{x}} \mathrm{Si}_{136}$ materials are formed with greater $\mathrm{Na}$ loss under higher vacuum or rapid heating conditions. The in situ X-ray diffraction data and uncovering of the formation mechanism will help guide further investigations towards producing clathrate phases in thin film form on semiconductor substrates ${ }^{33}$ and to design new clathrates from Zintl phase precursors, including incorporation of $\mathrm{H}_{2}$ into the clathrate cage structures. ${ }^{31}$ 


\section{Acknowledgements}

This work, including PhD and PDRA support to PTH, was enabled by the EPSRC Portfolio grant EP/D504782 to PFM and PB in collaboration with CRA Catlow, and an EPSRC Senior Research Fellowship GR/T00757 to PFM. LAO thanks EPSRC for funding and MES thanks EPSRC and the University of Warwick for partial funding of NMR equipment. J. Gryko is thanked for invaluable advice on clathrate synthesis and the Daresbury SRS staff are praised for their considerable help with the in situ synchrotron experiments.

\section{Supporting Information}

Additional data are presented in this section, including further Rietveld diffraction refinement plots, structural data and variations in certain structural/thermal parameters during the main stages of the synthesis reaction. This information is available free of charge via the Internet at http://pubs.acs.org/.

\section{References}

(1) Cros, C.; Pouchard, M.; Hagenmuller, P. Compt. Rend. Acad. Sci. Paris sér II, 1965, 260,4764 .

(2) Kasper, J. S.; Hagenmuller, P.; Pouchard, M.; Cros, C. Science 1965, 150, 1713.

(3) Cros, C.; Pouchard, M.; Hagenmuller, P. J. Solid State Chem. 1970, 2, 570.

(4) Cros, C.; Pouchard, M.; Hagenmuller, P.; Kasper, J. S. Bull. Soc. Chim. France 1968, 7, 2737.

(5) Gallmeier, J.; Schäfer, H.; Weiss, A. Z. Naturforschg. 1967, 22b, 1080.

(6) Gallmeier, J.; Schäfer, H.; Weiss, A. Z. Naturforschg. 1969, 24b, 665.

(7) Zhao, J. T.; Corbett, J. D. Inorg. Chem. 1994, 33, 5721.

(8) Reny, E.; Gravereau, P.; Cros, C.; Pouchard, M. J. Mater. Chem. 1998, 8, 2839.

(9) Ramachandran, G. K.; Dong, J.; Diefenbacher, J.; Gryko, J.; Marzke, R. F.; Sankey, O. F.; McMillan, P.F. J. Solid State Chem. 1999, 145, 716.

(10) Bobev, S.; Sevov, S. C. J. Solid State Chem., 2000, 153, 92.

(11) Reny, E.; Yamanaka, S.; Cros, C.; Pouchard, M. Chem. Commun. 2000, 24, 2505. 
(12) Ammar, A.; Cros, C.; Pouchard, M.; Jaussaud, N.; Bassat, J.-M.; Villeneuve, G.; Reny, E. J. Phys. IV France 2005, 123, 29.

(13) Yamanaka, S. Dalton Trans. 2010, 39, 1901.

(14) Shevelkov, A.V.; Kovnir, K. Structure \& Bonding: Springer: 2010.

(15) Horie, H.O.; Kikudome, T.; Teramura, K.; Yamanaka, S. J. Solid State Chem. 2009, $182,129$.

(16) Nolas, G. S.; Cohn, J. L.; Slack, G. A.; Schujman, S. B. Appl. Phys. Lett. 1998, 73, 178.

(17) Cohn, J. L.; Nolas, G. S.; Fessatidis, V.; Metcalf, T. H.; Slack, G. A. Phys Rev Lett. 1999, 82,779 .

(18) Nolas, G.S.; Weakley, T. J. R.; Cohn, J. L. Chem. Mater. 1999, 11, 2470.

(19) Shujman, S. B.; Nolas, G. S.; Young, R. A.; Lind, C.; Wilkinson, A. P.; Slack, G. A.; Patschke, R.; Kanatzidis, M. G.; Ulutagay, M.; Hwu, S. J. J. Appl. Phys. 2000, 87, 1529.

(20) Blake, N. P.; Mollnitz, L.; Kresse, G.; Metiu, H. J. Chem. Phys. 1999, 111, 3133.

(21) Iversen, B. B.; Palmqvist, A. E. C.; Cox, D. E.; Nolas, G. S.; Stucky, G. D.; Blake, N. P.; Metiu, H., J. Solid State Chem. 2000, 149, 455.

(22) Chakoumakos, B. C.; Sales, B. C.; Mandrus, D. G.; Nolas, G. S. J. Alloys Comp. 2000, 296,80 .

(23) Dong, J. J; Sankey, O. F.; Ramachandran, G. K.; McMillan, P. F. J. Appl. Phys. 2000, $87,7726$.

(24) Tse, J. S.; Uehara, K.; Rousseau, R.; Ker, A.; Ratcliffe, C. I.; White, M. A.; Mackay, G. Phys. Rev. Lett. 2000, 85, 114.

(25) Kawaji, H.; Horie, H.; Yamanaka, S.; Ishikawa, M. Phys. Rev. Lett. 1995, 74, 1427.

(26) Yamanaka, S.; Enishi, E.; Fukuoka, H.; Yasukawa, M.; Inorg. Chem. 2000, 39, 56.

(27) Herrmann, R. F.W.; Tanigaki, K.; Kuroshima, S.; Suematsu, H., Chem. Phys. Lett. 1998, 283, 29.

(28) Gryko, J.; McMillan, P. F.; Marzke, R. F.; Ramachandran, G. K.; Patton, D.; Deb, S. K.; Sankey, O. F. Phys. Rev. B . 2000, 62, R7707.

(29) Ramachandran, G. K.; McMillan, P. F.; Dong, J.; Sankey, O. F. J. Solid State Chem. 2000, 154, 626.

(30) Tang, X. L; Dong, J. J; Hutchins, P.; Shebanova, O.; Gryko, J.; Barnes, P.; Cockcroft, J. K.; Vickers, M.; McMillan, P .F. Phys. Rev. 2006, B 74, 014109.

(31) Neiner, D.; Okamoto, N. L.; Condron, C. L.; Ramasse, Q. M.; Browning, P. Y.; Nigel D.; Kauzlarich, S. M. J. Amer. Chem. Soc. 2007, 129, 13857. 
(32) Wilson, M.; McMillan, P. F. Phys. Rev. Lett. 2003, 90, 135703.

(33) Narita, T.; Ueno, H.; Baba, T.; Kume, T.; Ban, T.; Iida, T.; Habuchi, H.; Natsuhara, H.; Nonomura, S. Phys. Status Solidi C, 2010, 7, 1200.

(34) Jupe, A. C.; Turrillas, X.; Barnes, P.; Colston, S. L.; Hall, C.; Häusermann, D.; Hanfland, M. Phys. Rev. B 1996, 53, R14697.

(35) Polak, E.; Munn, J.; Barnes, P.; Tarling, S. E.; Ritter, C. J.Appl.Cryst. 1990, 23, 258.

(36) Jacques, S. D. M.; Leynaud, O.; Strusevich, D.; Beale, A. M.; Sankar, G.; Martin, C. M.; Barnes, P. Angew. Chem. 2006, 45, 445.

(37) Cernik, R.; J. Barnes, P.; Bushnell-Wye, G.; Dent, A. J.; Diakun, G. P.; Flaherty, J. V.; Greaves, G. N.; Heely, E. L.; Helsby, W.; Jacques, S. D. M.; Kay, J.; Rayment, T.; Ryan, A.; Tang, C. C.; Terrill, N. J. J. Syncr. Rad. 2004, 11, 163.

(38) Berry, A.; Helsby, W. I.; Parker, B. T.; Hall, C. J.; Buksh, P. A.; Hill, A.; Clague, N.; Hillon, M.; Corbett, G.; Clifford, P.; Tidbury, A.; Lewis, R. A.; Cernik, R. J.; Barnes, P.; Derbyshire, G. E. Nucl. Instrum. Meth. Phys. Res. 2003, A 513, 260.

(39) Rodríguez-Carvajal, J. Physica B: Condensed Matter 1993, 192, 55.

(40) Roisnel, T.; Rodríguez-Carvajal, J. Mater. Sci. Forum, Proc.7th Europ. Powder Diffraction Conf. (EPDIC 7) 2000, 118.

(41) Le Bail, A. Powder Diffraction. 2005, 20, 316.

(42) Rietveld, H. M. J. Appl. Cryst. 1969, 2, 65.

(43) Witte, J.; von Schnering, H. G. Z. Anorg. Allg. Chem. 1964, 327, 260.

(44) Hutchins, P. T. PhD thesis "In Situ Synthesis Studies of Silicon Clathrates"; University of London, 2007.

(45) O’Dell, L. A.; Savin, S. L. P.; Chadwick, A. V.; Smith, M. E. Faraday Discuss. 2007, $134,83$.

(46) Quesada Cabrera, R.; Barkalov, O. I.; Leynaud, O.; Hutchins, P.; Salamat, A.; Sella, A.; McMillan, P.F. J Solid State Chem. 2009, 182, 2535.

(47) Klemm, W. Proc. Chem. Soc. 1958, 329.

(48) Chemistry, Structure and Bonding of Zintl Phases and Ions, ed. Susan M. Kauzlarich, VCH Publishers, NY, 1996.

(49) Smith, M. E.; van Eck, E. R. H. Prog. Nucl. Magn. Reson. Spectrosc. 1999, 34, 159.

(50) Gryko, J.; McMillan, P. F.; Sankey, O. F. Phys. Rev. B. 1996, 54, 3037.

(51) Reny, E.; Ménétrier, M.; Cros, C.; Pouchard, M.; Sénégas, J. Comptes Rendus Acad. Sci. Paris sér II. 1998, 1, 129. 
(52) Böhme, B.; Guloy, A.; Tang, Z.; Schnelle, W.; Burkhardt, U.; Baitinger, M.; Grin, Y. J. Amer. Chem. Soc. 2007, 129, 5348.

(53) Beekman, M.; Nenghabi, E. N.; Biswas, K.; Myles, C. W.; Baitinger, M.; Grin, Y.; Nolas, G. S. Inorg. Chem. 2010, 49, 5338.

\section{Tables}

\begin{tabular}{|c|c|c|c|}
\hline \multicolumn{2}{|c|}{ NaSi } & \multicolumn{2}{c|}{ Na8Si $_{46}$} \\
\hline hkl & $\mathbf{2 \theta}\left(^{\circ}\right)$ & $\boldsymbol{h k l}$ & $\mathbf{2 \theta}\left(^{\circ}\right)$ \\
\hline-202 & 16.0996 & 200 & 15.7358 \\
\hline-221 & 28.1222 & 222 & 27.4309 \\
\hline-314 & 31.9186 & & \multirow{2}{*}{400} \\
\cline { 1 - 2 } & 32.0165 & & 31.7786 \\
\hline 204 & 32.0175 & & \\
\hline
\end{tabular}

Table 1. Related reflections between the two structures, starting as NaSi phase reflections (left 2 columns) and propagating eventually into Si-clathrate reflections (right 2 columns). (the 400 cannot be accurately assigned so all three potential candidates are given) 


\section{Captions for Figures}

Figure 1. (a) Powder X-ray in situ diffraction patterns obtained during the heating of $\mathrm{NaSi}$ in vacuum $\left(10^{-4}\right.$ bar $)$ to produce $\mathrm{Na}_{8} \mathrm{Si}_{46}$ clathrate. The diagram shows every $15^{\text {th }} 30 \mathrm{~s}$ pattern in a stacked plot, so the spacing between the displayed patterns represents 7.5 minutes. The temperature was ramped from room temperature up to $500^{\circ} \mathrm{C}$ at $8^{\circ} \mathrm{C} / \mathrm{min}$ after which it was held constant. The small data gap, at just over halfway, is due to a necessary interruption of the X-ray beam while the vacuum system liquid nitrogen was being topped up. The loss of diffraction intensity with the last four patterns was due to the destruction of the sample capillary following attack by $\mathrm{Na}$ vapor released during the synthesis reaction. It is clear that all the significant structural changes occur during the first 10 patterns which corresponds to a time period of 75 minutes and a top temperature of $500^{\circ} \mathrm{C}$.

(b,c) More detailed views of the time-resolved diffraction data collected within the regions indicated by the two boxes shown in Figure 1a (here, every $8^{\text {th }} 30 \mathrm{~s}$ pattern is shown, giving a spacing of 4 minutes between the displayed patterns; the $2 \theta$-angle ranges are: (a) $12-26^{\circ}$; (b): $24-38^{\circ}$ ). The continuous shifting of peaks, from NaSi precursor to Si-clathrate product, is very clear.

Figure 2. A "Rietveld" diffraction plot (Intensity in arbitrary units versus $2 \theta\left(^{\circ}\right)$ ) from the sample at $500^{\circ} \mathrm{C}$ after 150 minutes, this being the end point of the synthesis. The data are fitted as a two-phase model to the NaSi and Si-clathrate structures: points $=\mathrm{Y}_{\mathrm{obs}}=$ observed diffraction data; upper line $=\mathrm{Y}_{\text {calc }}=$ calculated diffraction data from the model; lower line $=$ $\mathrm{Y}_{\mathrm{obs}}-\mathrm{Y}_{\mathrm{calc}}=$ difference between these two; vertical bars are the predicted positions of the Bragg diffraction peaks (upper $=$ clathrate, lower $=$ NaSi peaks) showing significant peak overlap with the two structures. Further examples of Rietveld plots, together with associated refinement/structural data, can be found in the Supplementary Information.

Figure 3. In situ thermal expansion data, over the ranges of existence of the $\mathrm{NaSi}$ and $\mathrm{Si}$ clathrate phases, during the clathrate synthesis: The unit cell volumes are shown against time or temperature using the displayed temperature ramp profile and probabilistic error bars (as derived from the obtained unit cell refinement) are given for representative points on both data sets. The NaSi exhibits unusually large expansion up to the synthesis point (near $500^{\circ} \mathrm{C}$ ) after which it drops to lower values; by comparison, the Si-clathrate cell increases slowly 
against time (NB: the scale for the clathrate data is ten times more sensitive) though this increase is during a regime of constant target $\left(500^{\circ} \mathrm{C}\right)$ temperature. .

Figure 4. Structural graphics for the NaSi and Si-clathrate phases obtained using the CCDC (Cambridge Crystallographic Data Centre) Mercury Structure Visualization Program, with standard slice/ packing/depth parameters; some atoms have been interactively removed at the fringes so as to aid viewing:

(a) View of the NaSi structure down the [-202] direction such that one is looking down onto (-202) planes which are related, diffraction-wise, to the clathrate (200) planes indicated in Figure $4 b$.

(b) View of the Si-clathrate $\left(\mathrm{Na}_{8} \mathrm{Si}_{46}\right)$ structure such that the (200) planes (indicated) are seen "sideways on".

(c) An alternative "sideways" view (to (a)) of the NaSi structure (looking down the [C2/c] direction) which clearly shows the -202 plane effectively cutting through the "sheet" of Nacations.

Figure 5: ${ }^{23} \mathrm{Na}$ NMR spectra obtained during heating of the NaSi phase from ambient to $400^{\circ} \mathrm{C}$ as for the synthesis of the Si-clathrate phase. The spectra are stacked and arbitrarily separated by temperature for comparison.

Figure 6: In situ diffraction patterns stacked upwards, covering ca 9 cycles of heating/cooling ramps, applied to the NaSi pre-curser phase as would be used in a Si-clathrate synthesis. The temperature "sawtooth" profile is indicated on the left side: each "tooth" represents a separate ramp from ambient to a target temperature, which is initially $300^{\circ} \mathrm{C}$ but then increases each cycle by $25^{\circ} \mathrm{C}$ until the full synthesis $500^{\circ} \mathrm{C}$ maximum is reached, i.e. the sawteeth size progressively increases $\left(20 \rightarrow 300 \rightarrow 20 \rightarrow 325 \rightarrow 20 \rightarrow 350 \rightarrow 20 \rightarrow 375 \rightarrow \ldots . .500^{\circ} \mathrm{C}\right)$. Each pattern represents 59 seconds and every $4^{\text {th }}$ pattern is shown; the diffraction intensity scale is arbitrary. The large arcs described by each diffraction peak reflect the large thermal expansions/contractions of NaSi during the thermal cycling. The new diffraction peaks (e.g. between $28^{\circ}-29^{\circ}$ and $32^{\circ}-33.5^{\circ}$ ) begin to be observed above $\sim 300^{\circ} \mathrm{C}$ but only become permanent after $\sim 6$ cycles to $\mathrm{T}>425^{\circ} \mathrm{C}$, after which they track more closely the $\mathrm{NaSi}$ expansions/contractions. 
Figures

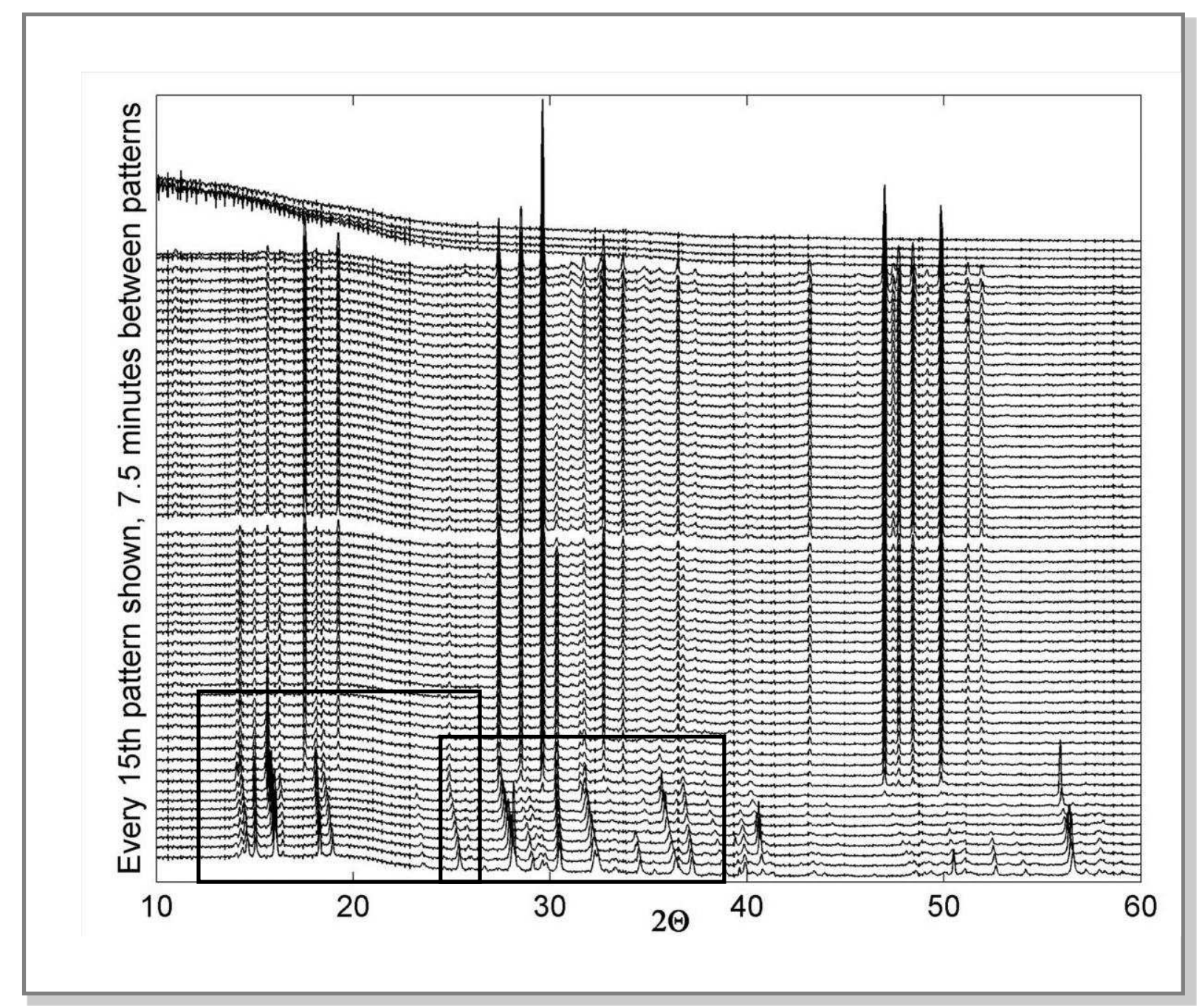

Figure 1a 


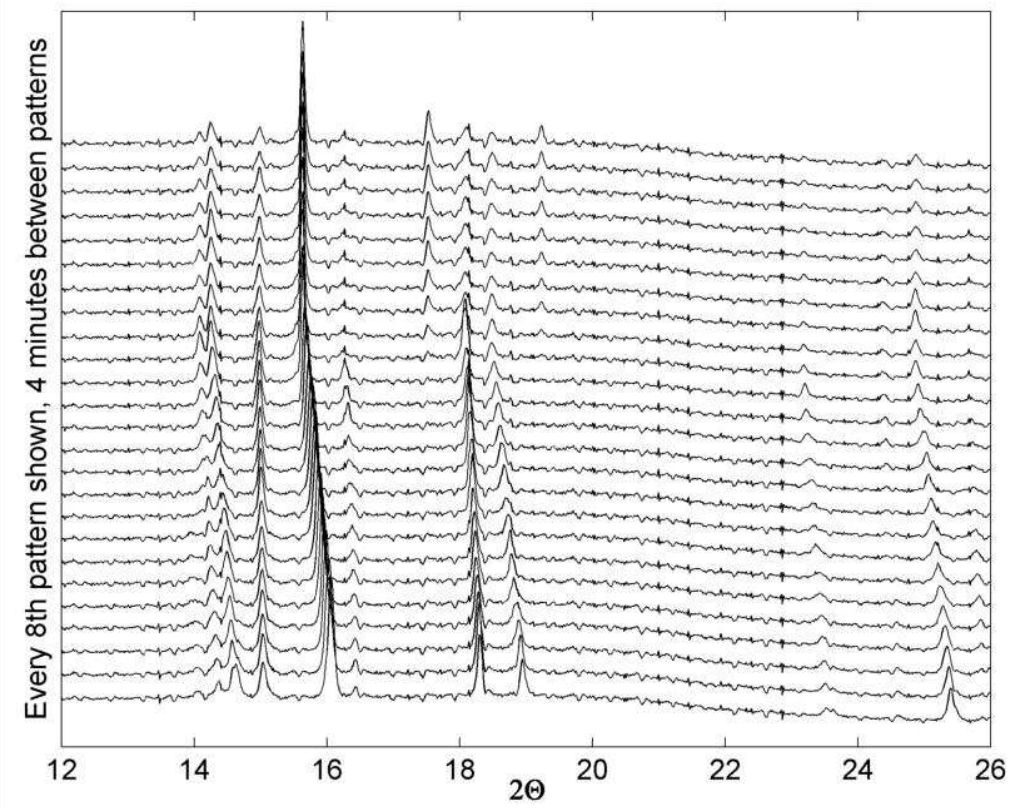

Figure 1b

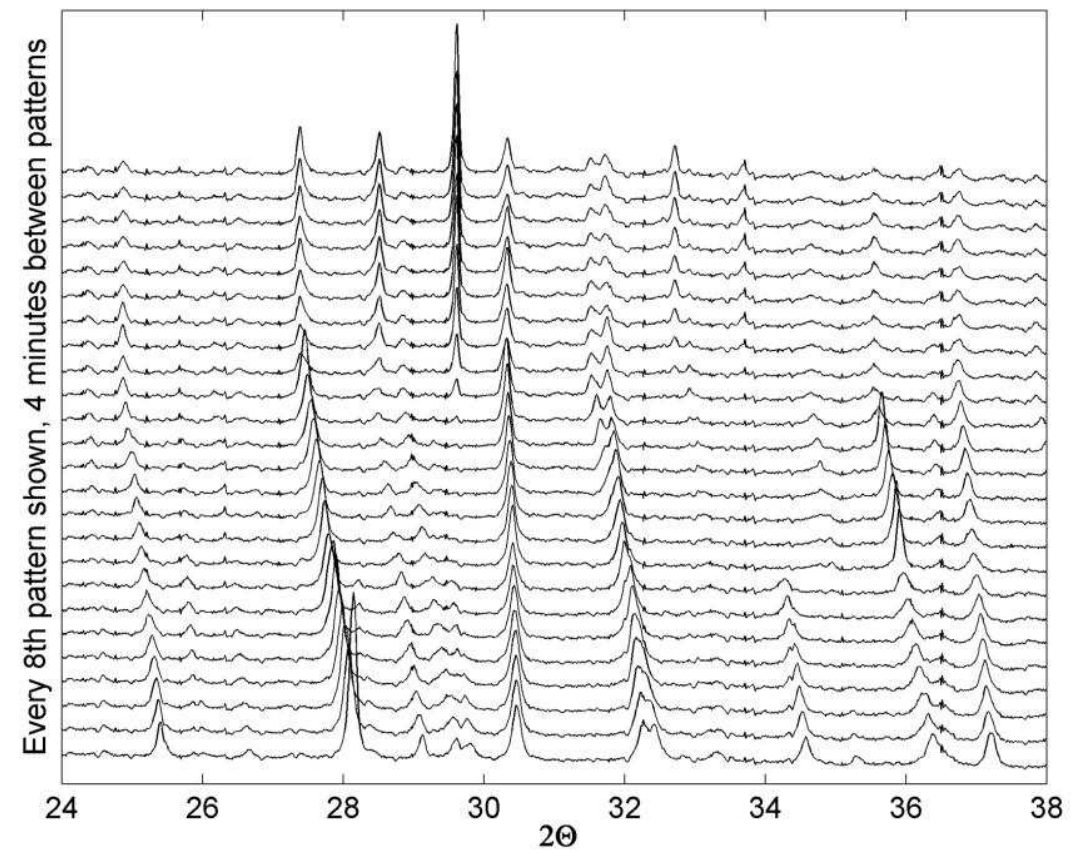

Figure 1c 


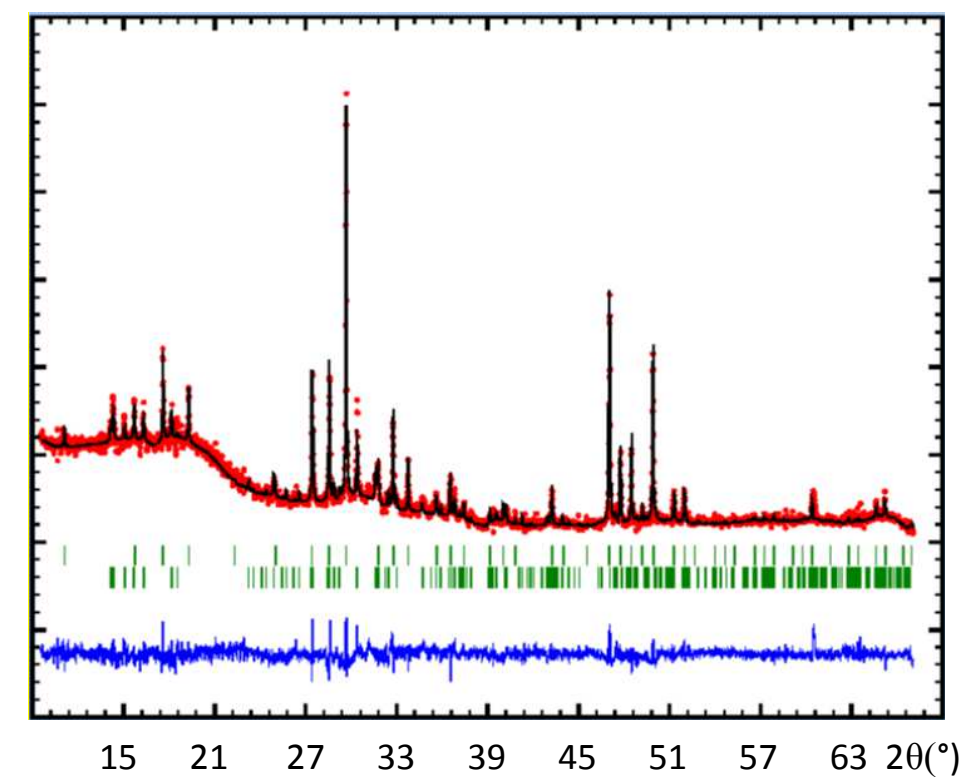

Figure 2 


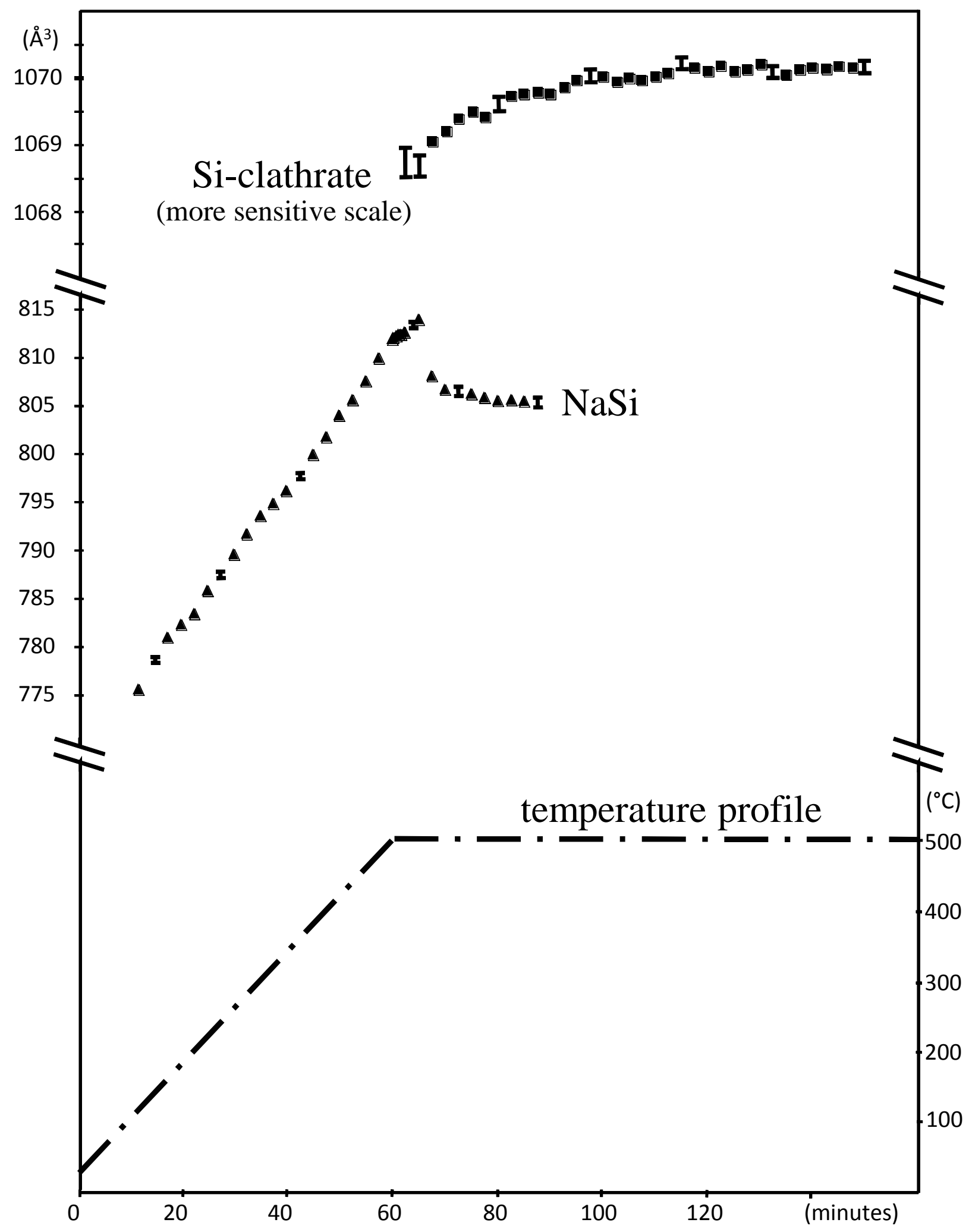

Figure 3 


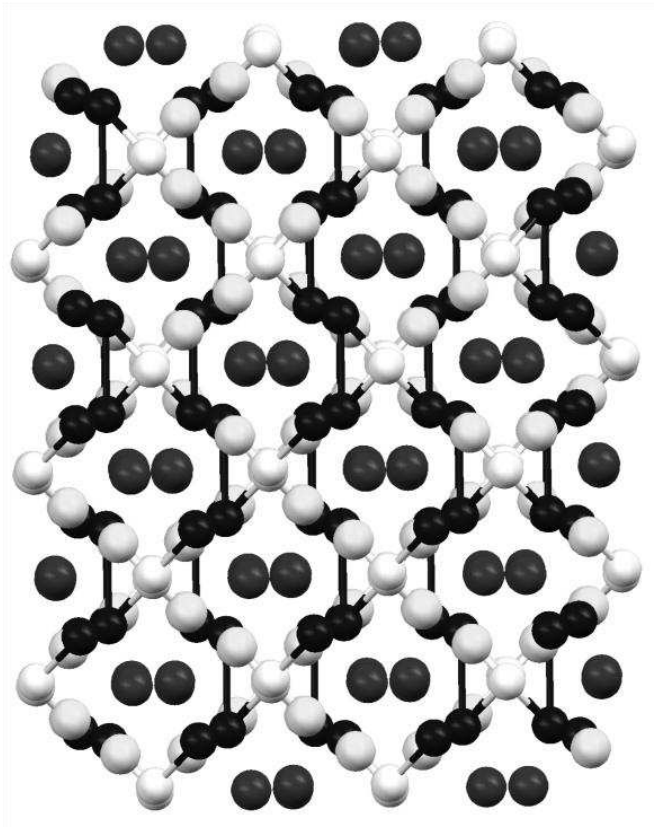

Figure 4a

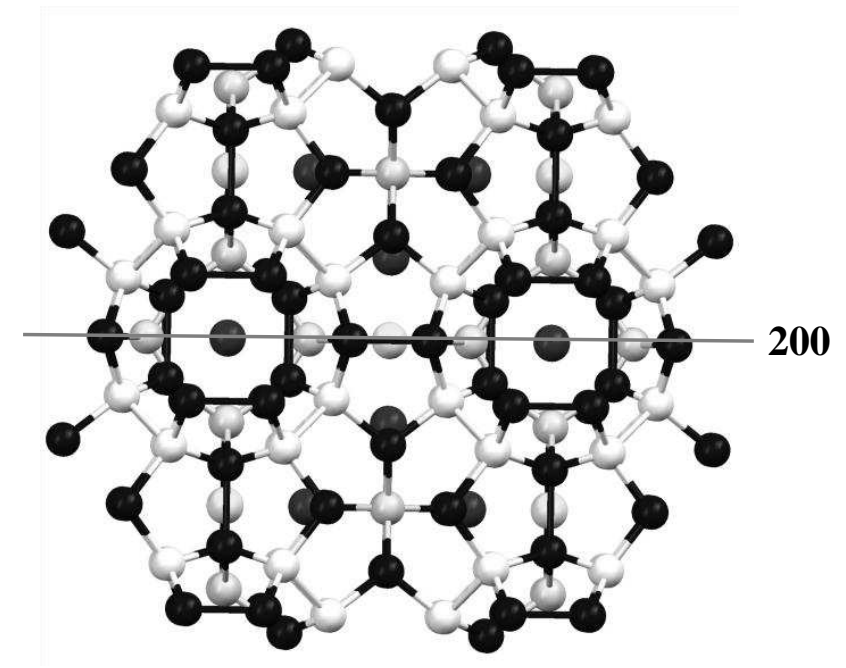

Figure 4b

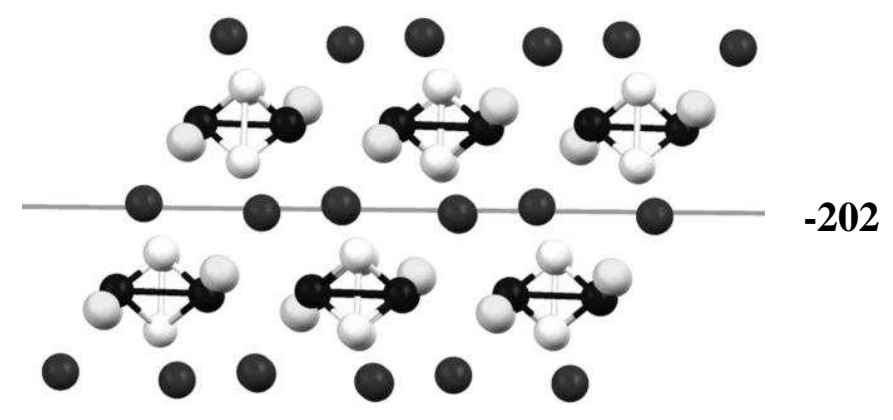

Figure 4c 


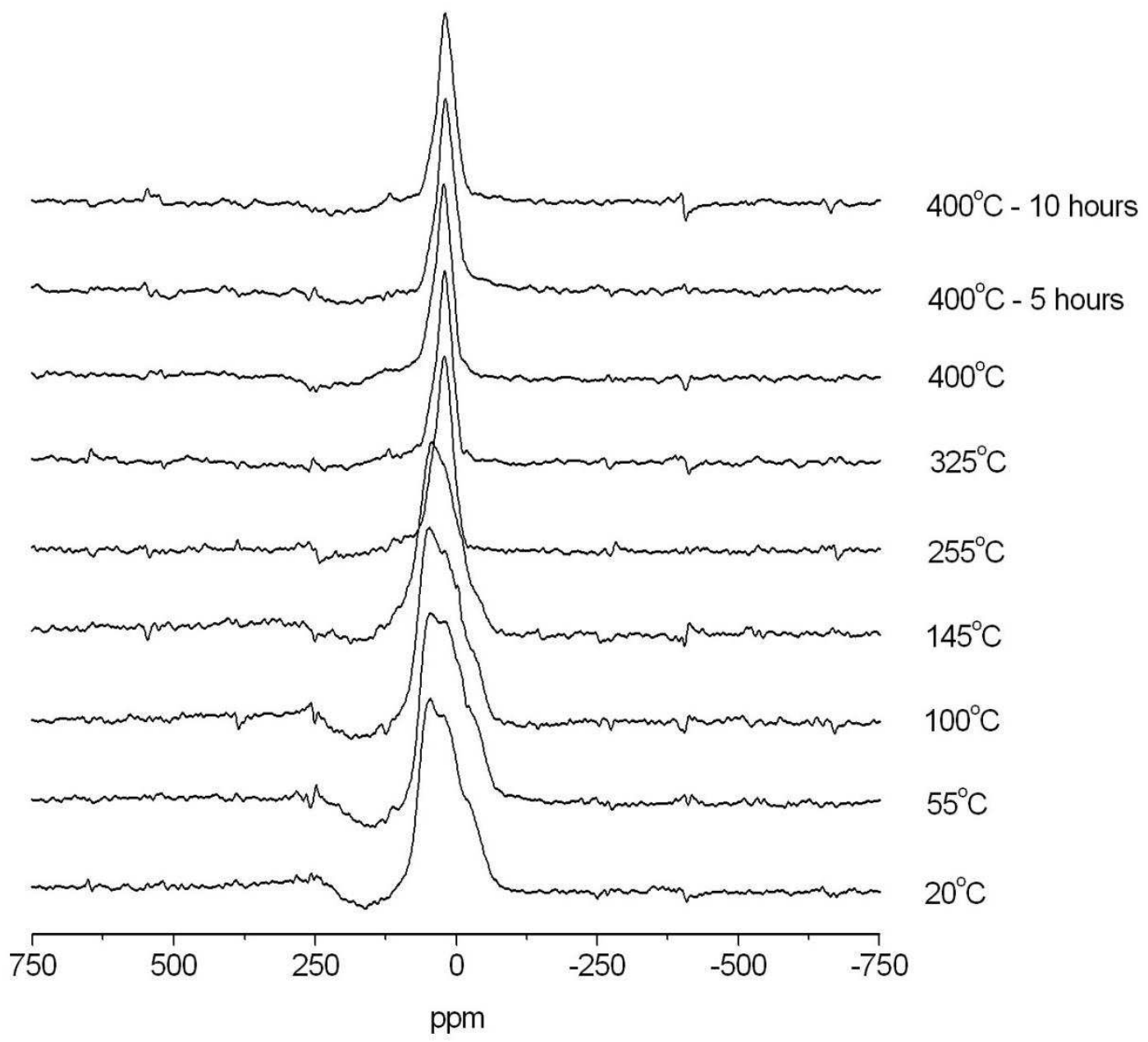

Figure 5 


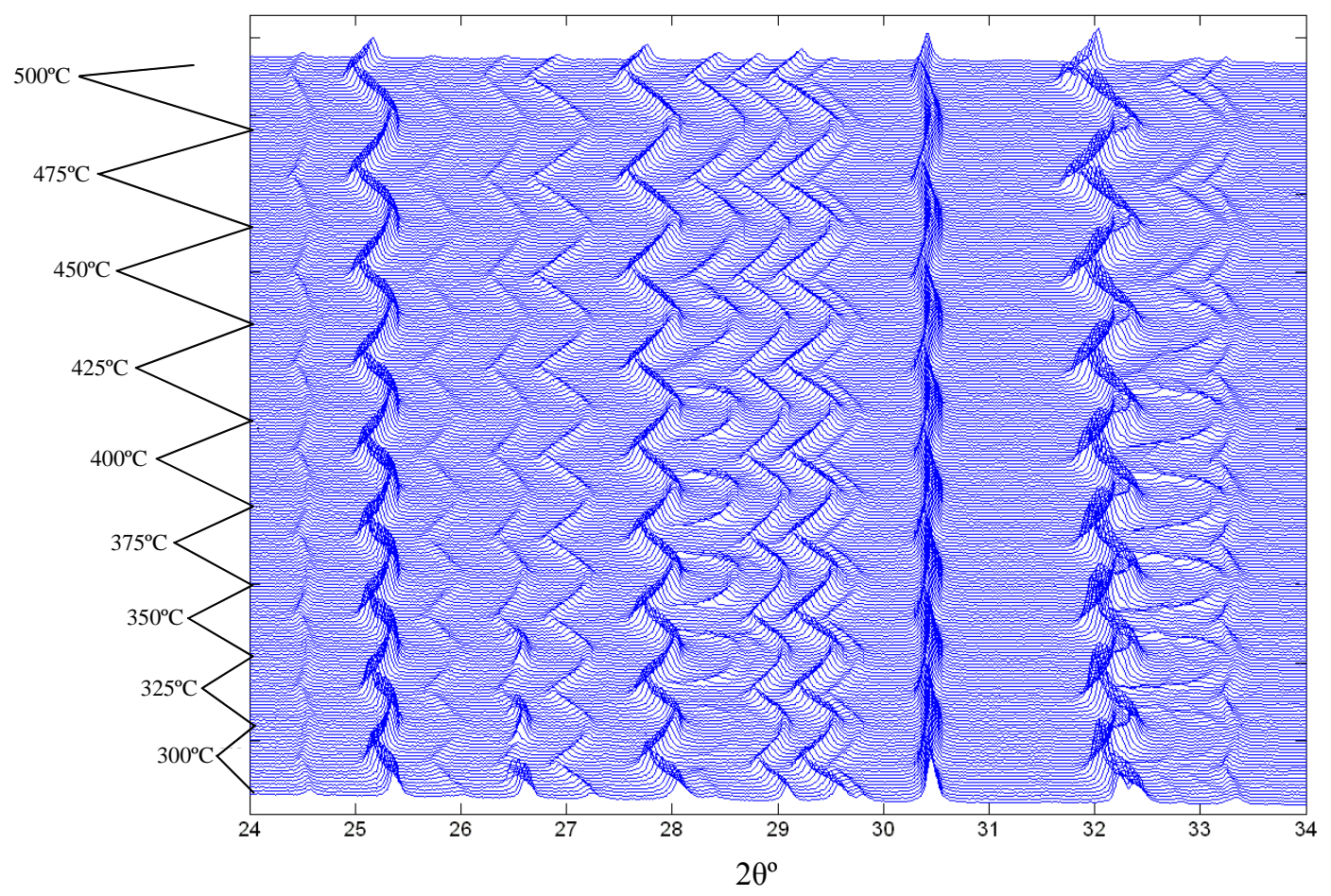

Figure 6 


\section{Contents Graphic and Summary}

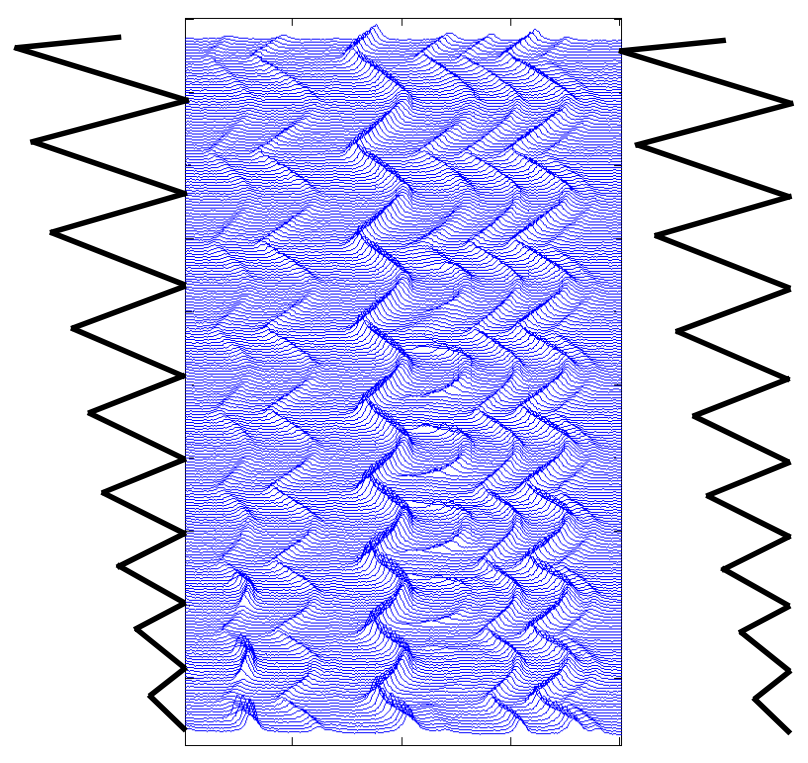

Rapid in situ synchrotron X-ray diffraction data suggest an unusual epitaxial synthesis of type-I $\mathrm{Na}_{8} \mathrm{Si}_{46}$ clathrate: the precursor $\mathrm{NaSi}$, on losing $\mathrm{Na}$, provides a template for clathrate formation. Cyclic diffraction-heating data give a "barchan dune" appearance resulting from the large thermal expansion of the Zintl and derivative phases. 